\title{
Characteristics and Prospects Analysis of China's Regional Coordinated Development of Regional Economy
}

\author{
Min Song \\ Chang Chun Vocational Institute of Technology, Changchun, Jilin province, 130033, China
}

\begin{abstract}
According to proposed research methods of national coordinated development of regional economy, we calculated national coordinated development degree of regional economy in recent year and analyzed the trend and characteristics. The result shows that: the overall level of national coordination development of regional economy improved significantly, reaching a higher level of coordination.
\end{abstract}

Keywords-regional economy; coordinated development; income.

\section{CHARACTERISTICS OF CHINA'S REGIONAL COORDINATED DEVELOPMENT OF REGIONAL ECONOMY}

First, the objective requirements of the development trend of integration of worldwide regional economy. After World War II, the economy in most countries has been seriously impacted by the war, so all the countries put the post-war economic construction in an important position, what is particularly worth mentioning is the trend of regional economic development gradually become dominant in the process of countries economic development. From this trend of world economic development, we can see that both developed and developing countries, want to actively participate in the process of regional economic integration, and in the process of regional economic development, in order to achieve scale merit and dominance complementation. Coordinated regional economic development inside a country is a microcosm of global regional economic integration.

The mode of China's regional economic development shifts radically. The chief architect of China's reform and opening policy put forward the basic idea of regional economic developing strategy in the central work conference for the first time: let some people and some regions get rich first, and drive other people and regions then, "making national economy continue developing in waves, so that people of all nationalities can get rich soon.”

The guiding principle of this strategic vision is that by putting efficiency in the first place, taking fairness into account and encouraging the prior development of some areas where conditions permitted, and driving economy in other areas by radiation from developed economy, we can achieve common development. Practice has proved that, in promoting co-developing process of regional economy, the lack of "fairness" has brought serious consequences which shows the expanding gap between eastern, central and western economic growth rate; the gap of industrialization and urbanization level among regions is widening; the inter- regional gap of per capita GDP and per capita disposable income is also expanding significantly; in addition, there are significant differences in the industrial structure and the level of overall social development between the East and Midwest. Third, adhering to the scientific concept of development is a necessary requirement to build a harmonious society. Harmonious socialist society should be a society embodying democracy and legality, fairness and justice, honesty and friendship, vigor and security, maintenance of social order and concord between the nature and man. "Promoting coordinated regional development, is not only a strategic task of reform and opening up and socialist modernization, but also an inevitable requirement of building a well-off society in an all-round way, building a harmonious socialist society. The whole Party and the entire country must implement the scientific concept of development, build up a harmonious socialist society strategic perspective, and understand the significance of promoting coordinated regional development profoundly.

\section{HISTORICAL ANALYSIS OF REGIONAL ECONOMIC DEVELOPMENT}

Although China has more than 10 years of practice of promoting the coordinated development of regional economy, but so far, there still exists different understanding on the connotation of coordinated development of regional economy the academic world. This leads to different evaluation of regional economic development. Currently, most scholars believe, coordinated regional economic development belongs to inter-regional economic relations category, but there are also some scholars taking coordinated regional economic development as the tune of each subsystem such as co-population, economy, society, resources and environment within the region. From the original intention our country proposed for the promotion of regional coordinated economic development strategy and the series of policy measures implemented, we see promoting the coordinated regional economic development issues is to solve the imbalance and incoordination of the economic development among regions, and therefore, evaluation on coordinated regional economic development is essentially analysis and judgment on the coordination of economic development between regions. If we take coordinated regional economic development as the coordination the various subsystems inside the region, it essentially belongs to the scope of the regional sustainable development. This is easy to see from the connotation of sustainable development. We define 
coordinated regional economic development as follows: "coordinated regional economic development in the region refers to, the process of the increasingly close economic ties between the regions, deepening economic interdependence, the associated interaction and the positive promotion in economic development, sustainable development of the regional economy and the downward trend regional economic disparity under the open condition.” According to this definition, there are three standard to determine whether the development of regional economy is coordinated: inter-regional economic ties, regional economic growth, regional economic differences. Analysis on national regional coordinated economic development is based on taking 31 provinces, municipalities and autonomous regions as regional units, the four regions on its interior provinces, municipalities and autonomous regions, provinces and autonomous regions on prefecturelevel cities inside the provinces, and municipalities on counties under their jurisdiction.

\section{EXPERIENCE OF NATIONAL REGIONAL COORDINATED ECONOMIC DEVELOPMENT}

Overall, the level of the national regional economic development promoted significantly. From 2001 to 2010, national coordinated development of the regional economy rose from 0.1264 to 1 , with an increase up to $691.2 \%$. At present, the national regional economic development has reached a higher level of coordination. This suggests that a series of strategies and politic measures taken by our country to promote the coordinated development of regional economy has achieved good results. It is worth noting that after 2004, the national coordinated development of the regional economy appeared two fluctuations, especially a substantial decline in 2007-2009, which caused a drop of $70.2 \%$. In 2009-2010, the national regional coordinated development of the economy decline was changed into rapid increase. This changing process, on one hand suggests the international financial crisis had a significant impact on the national regional economic development, on the other hand shows that the countermeasures, especially the series of regional planning and policy intensively introduced China adopted to stimulate regional economic development potential and vitality, and to promote regional economic development, have not only weathered by the impact of the international financial crisis, and safeguarded the sustained and stable growth of the national economy, but also reversed the downward trend of the coordinated development of regional economy. Seen from the process of regional economic coordinated development in the central regions, the national implementation of the strategy for promoting the rise of the central region in 2004, , have played an active role in enhancement of internal coordination of regional economic development in central China , and curbed the downward trend of degree of coordinated development since 2001.In response to the impact of the international financial crisis, actions in each province of the central region, improved the policy system in central region further, and has played a positive role in promoted the coordinated development of regional economy, to resist the impact of the international financial crisis effectively.

\section{PROBLEMS ARISEN IN COORDINATION IN THE IMPLEMENTATION OF REGIONAL ECONOMIC DEVELOPMENT STRATEGY IN CHINA}

Regional coordinated development is the prerequisite for smooth, healthy and efficient operation of the national economy, important content and main task of scientific view, and the prerequisite for sustainable development in China. Difference in regional economic development is an objective fact in China's economic and social development. Appropriate regional development disparities help stimulate vitality in competition among regions, but a big gap in regional development, will restrict the development of the whole region in China, thereby affecting the social fairness and justice. Since the new era, to promote coordinated regional economic development, The Party Central Committee and the State Council has formulated and implemented a series of regional economic development strategies, and achieved remarkable results. However, due to the discrepancy between theory and practice, as well as the restriction of objective and subjective factors, there were many problems during the implementation process of regional economic coordinated development strategy, to which caused the Party Central Committee and the State Council attach great importance. In the 39th learning conference in Political Bureau of the Central Committee, it is pointed out to "put balanced development among regions in a more important position, and implement the total strategy of regional coordinative development effectively." It has fully demonstrated the concern that leadership had on the issue. The problems emerged during the implementation process of the regional economic coordinated development strategies in China in the new era are as follows:

\section{A. There exist unfocused problems in implementation of regional economic development strategy}

The realization of regional economic coordinated development relies heavily on the Central Government's working out a reasonable set of macro-regional policies and regional development strategies. Entering the 21st century, in order to realize the coordinated development of regional economies, China have taken corresponding development strategies in various regions, namely to implement the Western development strategy, to rejuvenate Northeast China and other old industrial bases, promote the central region rising strategy, and to encourage the eastern region to take the lead in developing strategy, hoping to form a mutual promotion and common development in regional economy. The main goal of this diversified strategy is to realize the coordinated development of regional economies, but due to macro properties and diversification of regional development strategies implementation, there are problems such as too many focuses, less prominent focus, leading to regional development strategy on plight of focuses fuzziness. 


\section{B. Regional economic development strategy implementation appears dilemma of target deviation}

While it is the economic area involved in regional development, but economic area and administrative are inextricably linked, and in general, the economic region is composed of several districts, therefore, achieving coordinated development of regional economy necessarily involves the interests of the governments in which divide administrative districts as a unit. In order to maximize the benefits of the country, competition among governments is inevitable. To some extent, the competition is in favor of technological development and optimal allocation of resources, and can promote economic development. However, if this competition is a vicious competition or unfair competition under the protection of local government, in the long run it is not only useless to sustained and healthy economic development, but also will aggravate further expanding of regional disparity. Implementation of regional economic coordinated development strategies encountered institutional obstacles. China is in the beginning of regional economic integration process, and it is regional institutional obstacles the fundamental reason that leads to China's domestic market segmentation, difficulties in establishing market with uniform product and factor, the role incompletely played by market mechanism in the allocation of resources inside the region, as well as the difficulties in forming industrial division with complementary advantages. These institutional barriers ultimately undermine the role of market mechanisms in resource allocation, the domestic market divided, which made the regional industrial division with the principle of comparative advantage difficult to form, and resulting in the incoordination of regional infrastructure, industry isomorph and redundant construction. Meanwhile, there exists outstanding contradiction between administrative and economic zones. To pursue their own achievements, local governments invest impulsively and expand haphazard, leading to redundant construction and industrial isomorphism, and seriously affects the efficiency of resource allocation. Now many baffling institutional obstacles of regional coordinated development have not been eliminated, restricting the implementation of China's regional development strategy.

\section{It lacks unified legal guarantee in the process of implementing coordinated regional economic development strategies}

In China, the existence of administrative divisions and local interests and the allocation of legislative power on the basis of the administrative divisions brought in the inevitability of regulation and policy conflict. "It lacks regional legal governing body. Lacking laws and coordination in regional governance which brings no legal basis for regional coordination, not only increases regional coordination costs, but also makes it impossible to upgrade the comprehensive benefits and achieve a reasonable distribution of resources." National implementation of the regional economy coordinated development policy lacks legal protection, laws and regulations in micro field prior to macro field, with the awkward phenomenon of policy conflicts arisen, and different political ideas in actual operation. Lacking a unified and coordinated regional policy, when implementing macro-control, China has not a strong target, which often results in policy convergence, the phenomenon of "across the board", and so on. Due to the lack of unified, coordinated regional policy, the trend of "princes 'economy" becomes more apparent. Various regulations and policies are formed in order to safeguard the regional interests, which will hinder the free movement of capital and goods. The objective existence of regional legal policy inconsistencies even conflicts leads to different competitive environment affects directly on the coordinated development of regional economy.

\section{SUMMARIES}

The formation of regional economic development gap is the coefficient result of history geography culture location policy and other factors, coordinated regional development strategy arising for addressing regional uncoordinated development, and regional coordinated development objectives, includes to narrow regional economic differences gradually, to make regional industrial division and cooperation of labor become reasonable and competitions among region become rational and orderly, to realize the inter-regional and benefit-sharing mechanism and economic and social sustainable development in different regions, and so on. At present, China is facing the arduous developing task to accelerating economic growth pattern, spanning over the medium-developed countries trap to developed countries, but at the same time facing the multiple historic task on how to coordinate the eastern region with developing western region in advance, promoting the development of the central region and the revitalization of old northeastern industrial bases, and so on, for which we must find a comprehensive policy to achieve different targets.

\section{REFERENCES}

[1] Pi Jianchai. Leather was built research internal mechanism to coordinate regional economic development in China $[\mathrm{J}]$ economists, 2011, 12: 15-22.

[2] Sun Cuilan Review of China coordinated regional economic development study [J] Economic Survey, 2007,06: 57-59 + 78 .

[3] Cai Yusheng. Path of local government competition coordinated development of regional economy China - based on analysis of Chinese regional economic development strategy [J] realistic, 2006, 05: 35-37.

[4] Gao Peiyong. Fiscal policy in the 21st century China's regional economic development analysis [J] Financial Research, 2001, 03: 2328.

[5] Wei Houkai objectives and policy coordination of regional economic development in China (on) [J] Economic Review, 1994, 03: 5-9.

[6] Li Xinan Chinese regional economic development policy and regulatory mechanisms study [J] Xinjiang Social Science, 2002, 05: 16-20.

[7] Yuan Xiaoling, the potential economic growth rate and China regional economic development [J] Business Research, Jan. 2009: 2933. 